\title{
Aprendizagens em Rede: Cooperação interinstitucional na atuação da Rede Internacional de Pesquisa Resiliência Climática - RIPEDRC
}

\author{
Network Learning: Interinstitutional cooperation in the performance of the International Climate \\ Resilience Research Network - RIPEDRC \\ Aprendizaje en Red: Cooperación interinstitucional en el desempeño de la Red Internacional de \\ Investigación Resiliencia Climática - RIPEDRC
}

Recebido: 08/07/2021 | Revisado: 17/07/2021 | Aceito: 22/07/2021 | Publicado: 29/07/2021

\author{
Irene Carniatto \\ ORCID: https://orcid.org/0000-0003-1140-6260 \\ Universidade Estadual do Oeste do Paraná, Brasil \\ E-mail: irenecarniatto@gmail.com \\ Michèle Sato \\ ORCID: https://orcid.org/0000-0001-9834-4642 \\ Universidade Federal de Mato Grosso, Brasil \\ E-mail: michelesato@gmail.com \\ Vilmar Alves Pereira \\ ORCID: https://orcid.org/0000-0003-2548-5086 \\ Universidade Internacional do Cuanza, Angola \\ E-mail: vilmar1972@gmail.com
}

\begin{abstract}
Resumo
Este artigo resulta do projeto de pesquisa de Pós-doutorado no Programa de Pós-Graduação em Educação da Universidade Federal de Mato Grosso, Brasil, que integra ensino, pesquisa e extensão. É desenvolvido em treze países e em inúmeros municípios, regiões e estados brasileiros. Uma pesquisa interdisciplinar que foi desenvolvida com pesquisadores da "Rede Internacional de Pesquisa Resiliência Climática - RIPEDRC". O estudo foi desenvolvido em três etapas: na primeira, apresenta um contexto da crise ambiental e suas interfaces com as emergências climáticas e a justiça climática, situando os tempos atuais como destacados por profundas mudanças em todos os campos do saber e da vida humana. Por conseguinte, a crise socioecológica e civilizatória instalada no planeta, apresentada neste estudo é reconhecida por Loureiro (2004), Leff (2006), Wilson (2008), Carniatto (2007), Lovelock (2010), Boff (2012), Zohar \& Marshall (2012), Carniatto; Rosa \& Oliveira, (2015), Serantes-Pazos \& Meira-Cartea (2016), Pereira \& Amaral (2020) e por Foster (2020). Na segunda etapa, situa o percurso metodológico mediante a pesquisa-ação e, finalmente, apresenta os resultados a partir da escuta sobre o sentido, alcances e potencialidades de cooperação na RIPEDRC, segundo as narrativas de pesquisadores integrantes desta rede. Os resultados atuais evidenciam quadros como grandes descuidos com a vida, de grupos sociais vulneráveis e pessoas socialmente excluídas e a RIPEDRC visa atender às emergências climáticas e à justiça climática no âmbito das comunidades. As respostas apontam para a significativa importância desta organização em rede no campo ambiental para o enfrentamento das principais questões relativas ao clima, de forma cooperativa e coletiva.
\end{abstract}

Palavras-chave: Rede de pesquisa; Emergência climática; Justiça climática; Educação ambiental; Pandemia COVID19.

\begin{abstract}
This paper is a result of the Postdoctoral research project at the Post graduation Program in Education at Federal University of Mato Grosso, Brazil, which integrates teaching, research and extension. It has been developed in several Brazilian cities, regions and states as well as in thirteen countries. An interdisciplinary research was developed with some researchers from the "International Research Network Climate Resilience - RIPEDRC". The study was developed in three phases: the first one presents a context of the environmental crisis and its interfaces with climate emergency and climate justice. The nowadays periods are highlighted by deep changes in all fields of knowledge and human life. Therefore, the socio-ecological and human crisis settle on the planet, presented in this study have been recognized by Loureiro (2004), Leff (2006), Wilson (2008), Carniatto (2007), Lovelock (2010), Boff (2012), Zohar \& Marshall (2012), Carniatto; Rosa \& Oliveira, (2015), Serantes-Pazos \& Meira-Cartea (2016), Pereira \& Amaral (2020), and by Foster (2020). The second one shows the methodological path according to the action-research and, finally, presents results based on the participants' narratives, the meaning, scope, and cooperation potential in RIPEDRC by researchers who are members of this network. The results suggest scenarios such as great carelessness with life, vulnerable social groups and socially excluded people. So, RIPEDRC aims at addressing climate
\end{abstract}


emergencies and climate justice at the community. The answers point for a significant importance of this network organization both for the environmental field and coping the main issues associated to the climate in a cooperative and collective dynamic.

Keywords: Research network; Climate emergency; Climate justice; Environmental education; COVID-19 Pandemic.

\section{Resumen}

Este artículo es el resultado de un proyecto de investigación posdoctoral en el Programa de Posgrado en Educación de la Universidad Federal de Mato Grosso, Brasil, que integra docencia, investigación y extensión. Se desarrolla en trece países y en muchas ciudades, regiones y estados brasileños. Se desarrolló una investigación interdisciplinaria con investigadores de la "Red Internacional de Investigación Resiliencia Climática - RIPEDRC". El estudio se realizó en tres etapas: en la primera, presenta un contexto de la crisis ambiental y sus interfaces con las emergencias climáticas y la justicia climática, ubicando los tiempos actuales como destacados por cambios profundos en todos los campos del conocimiento y la vida humana. En consecuencia, la crisis socio ecológica y de civilización instalada en el planeta, presentada en este estudio es reconocida por Loureiro (2004), Leff (2006), Wilson (2008), Carniatto (2007), Lovelock (2010), Boff (2012), Zohar \& Marshall (2012), Carniatto; Rosa \& Oliveira, (2015), Serantes-Pazos \& Meira-Cartea (2016), Pereira \& Amaral (2020) y por Foster (2020). La segunda etapa ubica el camino metodológico a través de la investigación acción y la tercera presenta los resultados a partir de la escucha del significado, alcance y potencial de la cooperación en RIPEDRC, según las narrativas de los investigadores miembros de esta red. Los resultados actuales muestran escenarios como un gran descuido con la vida, grupos sociales vulnerables y personas socialmente excluidas, y RIPEDRC tiene como objetivo abordar las emergencias climáticas y la justicia climática a nivel comunitario. Las respuestas apuntan a la significativa importancia de esta organización en red en el campo ambiental para enfrentar los principales temas relacionados con el clima, de manera cooperativa y colectiva.

Palabras clave: Red de investigación; Emergencia climática; Justicia climática; Educación ambiental; Pandemia de COVID-19.

\section{Introdução - Olhares Em Rede: O Contexto Socioecológico da Crise}

Nas últimas décadas do século passado e nas primeiras do atual, os problemas ambientais no Brasil têm se tornado cada vez mais críticos e frequentes, principalmente devido à expansão das atividades industriais, do crescimento populacional desordenado e das ocupações agropecuárias dos solos de maneira inadequada e políticas ambientais equivocadas, gerando alteração na qualidade e na distribuição dos recursos naturais (Cotta; Rezende; Piovani, 2006), degradando os ecossistemas, bem como ignorando os limites biofísicos da natureza (Carniatto, 2007).

Nesse sentido, convém ressaltar que esses são tempos marcados por profundas mudanças em todos os campos do saber e da vida humana. Pode-se dizer que a crise ambiental instalada no planeta é reconhecida como crise socioecológica (Carniatto, 2007; Carniatto; Rosa \& Oliveira, 2015; Foster, 2020;), de modo geral ela já está amplamente reconhecida por receber diversas denominações, como: crise civilizatória por Leff (2006), crise de sentido por Zohar e Marshall (2012), crise entre ciência e religião por Wilson (2008), como crise socioambiental por Loureiro (2004), Lovelock (2010), Boff (2012), Serantes-Pazos e Meira-Cartea (2016) e por Pereira e Amaral (2020).

Esta crise civilizatória demonstra vestígios de amplitude dos problemas que enfrentamos para defender a vida no planeta. Associado a isso há sinais evidentes de muitas patologias socioambientais (Pereira, 2020), cujas consequências estampam a grande crise socioambiental que a humanidade atravessa e que dificulta a vida de milhares de humanos e não humanos, em diferentes contextos do planeta terra. Nesse amplo horizonte, com múltiplas faces e em decorrência as mudanças climáticas expressam quadros como resultados de grandes descuidos com a vida.

Na gênese desse processo está o modelo de desenvolvimento econômico e o aumento das desigualdades em diferentes contextos nos quais os humanos sobrevivem em condições desumanas. Uma das decorrências são os problemas complexos, de grave perturbação no funcionamento do sistema social, afetando de forma desigual tanto os países e seus territórios (seus efeitos são mais visíveis nas zonas tropicais, ilhas e zonas costeiras, mas também nos grandes conglomerados urbanos), quanto à vida dos grupos sociais vulneráveis, que são pessoas empobrecidas e socialmente excluídas, sobretudo as mulheres e as crianças (Serantes-Pazos \& Meira-Cartea, 2016). Nesse amplo horizonte, com múltiplas faces e em decorrência as mudanças climáticas expressam quadros como resultados de grandes descuidos com a vida. 
É possível perceber que as populações que se encontram em situações mais vulneráveis são as populações que mais sofrem mediante a crise socioambiental. Estamos falando de pessoas em condição de rua, trabalhadores domésticos, indígenas, quilombolas, LGBTQI+, PcD, dependentes químicos, povos da floresta, populações ribeirinhas, trabalhadores, prestadores de serviços, pequenos comerciantes, moradores de comunidades periféricas, população negra, pequenos produtores rurais. Pessoas que constituem uma grande parcela do povo brasileiro, que vivem no campo ou em áreas urbanas de grande vulnerabilidade, entre tantos povos que reivindicam maior compromisso político e responsabilidade socioambiental de cada um de nós (Pereira \& Amaral, 2020).

É, portanto um problema marcadamente desigual, resultante do modelo de desenvolvimento econômico, em que os verdadeiros responsáveis pelo consumo massivo dos recursos e produtores dos gases de efeito estufa, não são os que sofrem efetivamente as consequências, mas sim são os que menos contribuem para o problema que sofrem com o mesmo, tratando-se, portanto de um de problema que Sato (2014) denomina de Injustiça Ambiental Climática em diferentes contextos, em que pessoas sobrevivem em condições desumanas. Desse modo entende-se que:

Em outras palavras, o clima é um dos temas que perfaz os movimentos de governança para que os povos vulneráveis consigam ter autonomia no mandato político de seus territórios, com capacidade de escolhas e marcos decisórios próprios que estejam em consonância com a inclusão social e a proteção ambiental (Sato, 2014, p.8).

Conjunturas como essas requerem ações cujo referencial considere a perspectiva das políticas públicas e da inovação, a qual prevê articulações da comunidade e que reivindica uma inovação social cooperativa para o enfrentamento de problemas eu afetem o contexto comunitário (Miranda, 2020).

Igualmente requer perspectivas de pesquisas que considerem a transdisciplinaridade como uma condição necessária para tamanho enfrentamento. Nesse horizonte, se insere a perspectiva de trabalho em rede, a qual privilegia o olhar transdisciplinar, integral, abrangente e sistêmico onde as questões e problemas relacionados às vulnerabilidades socioambientais e climáticas serão olhados a partir de diferentes campos do saber por diferentes especialistas.

Essa perspectiva abrangente e integral permite reconhecermos que a ecologia é mais do que o gerenciamento de recursos escassos e, portanto, assume-se em múltiplas dimensões: ambiental, política e social, mental e integral que reivindicam olhares transdisciplinares (Boff, 2012).

Segundo Kobiyama, et al. (2006) cabe à universidade compreender os mecanismos dos desastres, através de monitoramento, diagnóstico e modelagem, de maneira que essas informações sejam repassadas à sociedade, a fim de diminuir os danos provocados. Extrapolando esses conceitos, entende-se que a universidade, enquanto lócus de geração de conhecimento, cabe a ela compreender, estudar, pesquisar, debater o momento atual que a sociedade atravessa e desenvolver mecanismos de enfrentamento e soluções para problemas dos âmbitos locais, regionais, nacionais e planetários.

Assim, compreendendo esse desafio a Universidade Estadual do Oeste do Paraná (UNIOESTE) juntamente com a University of York e com o apoio da University of Leeds (UK) criaram em 2019 a Rede Internacional de Pesquisa em Desenvolvimento Resiliente ao Clima - RIPEDRC - Rede Resiliência Climática, com o propósito de contribuir para a capacitação de profissionais das universidades, através da pesquisa integrada e num contexto local articular os gestores públicos, criando redes de mobilização e organização da comunidade, para a implementação de ações em diferentes níveis, desde o global até o local e promovendo interações entre diversos setores da governança e organizações, no preparo para enfrentar os desafios do cenário de emergências sociais vivenciados na atualidade.

\subsection{Horizontes Epistemológicos e Metodológicos do Estudo}

A partir do contexto exposto acima, o estudo toma como referência a perspectiva das Quatro Ecologias: Ambiental, 
Política/Social, Mental e Integral (Boff, 2012); "Ecologia Cosmocena como vertente da Ecologia Política e como expressão de uma Ecologia Ambiental e que pode ser reconhecida como uma Ecologia das diferenças", cujas contribuições podem ser importantes:

[...] no enfrentamento de questões tão urgentes no campo da educação ambiental (EA), que passam necessariamente, pelo olhar de uma ecologia ambiental e pela necessidade de políticas, cujo horizonte tenha como ponto de partida o reconhecimento de milhares de homens e mulheres, que historicamente vivem em situação de exclusão social e, portanto, em condições de grande vulnerabilidade, principalmente dado o agravamento causado pela pandemia do COVID-19 (Pereira \& Amaral, 2020).

Igualmente relevante na orientação do estudo, a concepção de racionalidade e saber ambiental de Leff (2011) para o enfrentamento da crise civilizatória, amplamente reconhecida como resultado de processos civilizatórios, demarcados por relações de domínio, da natureza pelo humano com o uso de uma racionalidade estratégica, fria e calculista voltada para fins cujos endereçamentos são o aumento do lucro e de poder.

Assim, almeja a proposição de alternativas que propiciem a articulação entre as Políticas Públicas Municipais que articulam as ações socioambientais, a fim de buscar alternativas de construção coletiva que envolvam ações que assegurem a sustentabilidade dos ecossistemas, melhoria da qualidade de vida, empoderamento dos atores e justiça social.

Para problemas dessa magnitude é igualmente necessário alternativas abrangentes em seu enfrentamento. Nesse sentido é que o projeto da Rede RIPEDRC pretende organizar ações que propiciem o protagonismo dos grupos sociais, proporcionar a organização das comunidades, tendo por referência a compreensão de que a Epistemologia Ecológica reivindica olhares transdisciplinares para esse meio ambiente, não no sentido reducionista - de meio ambiente - metade, mas sim de ambiente em seu sentido amplo, integrador dos mais diversos e diferentes tipos de ambiente (Boff, 2012).

Diante deste panorama, diversas organizações tendo como base as conferências e acordos da ONU, assinados pela maioria dos países membros, já reconhecem as mudanças climáticas como sendo o grande desafio da atualidade, que requer soluções em diferentes níveis de governança e escalas de ação (Gupta, 2007), sendo necessário haver interação entre processos sociais, econômicos, culturais e políticos a fim de enfrentar este desafio (Adger, Arnell \& Tompkins, 2005).

Atenção especial deve ser dada aos grupos sociais que vivem na invisibilidade e em situação de vulnerabilidade. Sato (2016, p.4), adverte que "os efeitos drásticos das mudanças climáticas terão proporção, magnitude e escala de forma desigual e injusta, acometendo mais as camadas economicamente desfavorecidas, os que vivem na periferia", e é nesse contexto que surge o termo injustiça ambiental.

O conceito de Justiça Climática está mais focado nos grupos sociais em situação de vulnerabilidade, pois são os mais afetados às catástrofes ambientais, seja pela ausência de políticas, de informações socioambientais ou impossibilidade financeira de ter acesso aos mecanismos de proteção. Para designar esse fenômeno de imposição desproporcional dos riscos ambientais às populações menos dotadas de recursos financeiros, políticos e informacionais, tem sido consagrado o termo injustiça ambiental (Acselrad, et al., 2009, p. 9, apud Souza \& Sato, 2019, p.62).

Nessa perspectiva, destacam-se ações que a Organização das Nações Unidas vem buscando o enfrentamento através dos Objetivos do Programa Intergeracional de Promoção da Igualdade de Gênero, Raça e Etnia; visando apoiar a implementação dos Planos Nacionais para as Mulheres atrelando as Políticas de Promoção da Igualdade Racial; os quais apresentam como objetivos a superação da pobreza, fome zero, uma agricultura sustentável; água potável, saneamento, energia limpa e acessível, vida na água, vida terrestre, cidades e comunidades sustentáveis, consumo e produção responsáveis e a promoção de ações contra mudança global do clima, além de tantas outras ações. Também estão em cursos diferentes campanhas como a Década Internacional dos Afrodescendentes (2015 - 2024) denunciando que "há extrema necessidade de que os países busquem enfrentar o racismo, a discriminação racial e a intolerância, destacando que o reconhecimento, a justiça e o desenvolvimento devem ser vistos como prioridades mundiais" (Amaral, Pereira \& Costa, 2018, p.466).

Esses amplos movimentos reforçam a necessidade de justiça climática como é apresentada correlacionando a 
vulnerabilidade às mudanças climáticas, ao entendimento de injustiça climática por Manfrinate, Sato e Pazos (2019, p.173),

como algo que ocorre quando uma determinada comunidade necessita suportar sozinha uma carga maior de degradação ambiental e maiores consequências de mudanças climáticas em nome do chamado bem-estar e desenvolvimento da sociedade.

E nesta linha que se aponta para uma Educação Ambiental que vem enlaçada aos "saberes ambientais que, compartilhados com a perspectiva orientada para o cuidado com a natureza, trazem o diálogo socioambiental, aliando cultura e natureza nesse campo pedagógico capaz de fazer emergir a educação como impulsionadora de transformações socioambientais" (Manfrinate, Sato \& Pazos, 2020, p.174).

Uma Educação Ambiental como possibilidades de promover mudança nas pessoas, e novas formas de relações que levem a novos comportamentos, valores sociais, expressa "como uma luta para desenvolver atitudes ecológicas nas pessoas e interligar na sociedade a cultura e a natureza" (Souza \& Sato, 2019, p.64). E neste importante diálogo não apenas abarca, mas abraça os saberes e as práticas tradicionais dos povos indígenas, quilombolas, povos da floresta, populações ribeirinhas, trabalhadores, população negra, pequenos produtores rurais, entre outros.

Mas no Brasil, estamos vivendo diante de um movimento de contradição, quando as políticas nacionais têm sido desmontadas no que diz respeito aos seus avanços socioambientais das últimas décadas, e no bojo desta outra direção política, ainda se depara com a negação da Ciência e desvalorização da pesquisa e das Universidades. Não existe atualmente um plano do governo que se traduza em valorização e direcionamento estratégico de apoio às Instituições de ensino, às universidades e de fortalecimento das pesquisas, as quais almejam proteger o ambiente, trazer o avanço tecnológico e salvar vidas.

Assim, nesse cenário a busca pela "internacionalização da educação superior constrói-se como um conceito-chave neste século, deslocando-se de uma posição periférica a uma posição central e imbricada a uma noção positiva de qualidade", estando voltada já não prioritariamente à investigação, mas além da função de pesquisa, a internacionalização tem como ponto principal o ensino (Morosini, 2017, p.288).

\section{Metodologia - Mapeamento Socioambiental das Identidades Sociais dos Sujeitos: Objetivos e Percurso Metodológico}

No que concerne aos objetivos desse estudo buscou-se através dos olhares dos pesquisadores, identificar e analisar as potencialidades de cooperação para projetos com atuação em rede e revelar as contribuições dos pesquisadores na sua atuação nos territórios e nas instituições aos quais pertencem. Igualmente, identificar os pontos considerados positivos e os principais méritos e as principais dificuldades sentidas no contexto da internacionalização.

No horizonte da hipótese de estudo busca-se afirmar que a perspectiva do trabalho da RIPEDRC enquanto um projeto de rede de pesquisa, criado no Brasil em 2019, contribuiu significativamente em processos educativos ao enfrentamento dos problemas oriundos no contexto da pandemia da Covid19; igualmente defende que tais desafios puderam ser superados através de aprendizagens e potencialidades coletivas que se mostraram efetivas e podem ser compartilhadas. Sendo a Rede RIPEDRC criada como uma parceria de cooperação internacional da University of York (Inglaterra) com a Universidade Estadual do Oeste do Paraná - UNIOESTE (Brasil) e apoio da University of Leeds (Inglaterra) no "Workshop Brasil-Reino Unido sobre o Financiamento do Desenvolvimento Urbano Resiliente ao Clima", realizado nos dias 09 a 13 de setembro de 2019, na Unioeste, Foz do Iguaçu, Paraná, Brasil.

Com foco no alcance da Rede RIPEDRC, esta pesquisa foi conduzida na perspectiva da abordagem quali-quantitativa, descritiva de natureza exploratória sendo que o processo metodológico que estabeleceu o eixo central da pesquisa foi a Pesquisa-Ação que tem por pressuposto que os sujeitos que nela se envolvem compõem um grupo com objetivos e metas 
comuns, interessados em um problema que emerge num dado contexto, com um ponto de início em uma determinada realidade social, na sua respectiva complexidade e busca construir novas práticas locais num processo de transformação (Reigada \& Tolzoni-Reis, 2004; Thiollent, 2011).

O estudo está apresentado em 3 etapas: Etapa 1 apresenta uma contextualização da crise ambiental associada aos grandes desafios de nosso tempo, dentre eles as mudanças climáticas e a necessidade da justiça climática. Realiza isso através de um estudo bibliográfico. Na Etapa 2, situa mediante a pesquisa-ação o percurso metodológico, usando como instrumento o questionário On-line @Google-form, apresentando o Perfil e Potencialidades da Rede RIPEDRC, com um diagnóstico pelo Mapeamento Socioambiental das Identidades Sociais dos Sujeitos (Silva \& Sato, 2012), realizado com todos os participantes da RIPEDRC, sendo que do total de 210 pesquisadores, 134 responderam e fizeram a adesão formal à Rede, no período de maio de 2020 a abril de 2021.

E finalmente, na Fase 3: São apresentados os dados obtidos em uma amostra composta por 10 pesquisadores convidados, assumidos nesse trabalho como representação da Rede RIPEDRC, sendo escolhidos aqueles de destacada participação na rede ou por representarem seu país, os quais participaram da pesquisa específica sobre as "Aprendizagens Coletivas: o papel da internacionalização na atuação da Rede RIPEDRC", realizada de setembro de 2020 a janeiro de 2021.

A pesquisa lança mão da Investigação Narrativa fundamentada na premissa que esses sujeitos são portadores de histórias suas e de outros, os quais com eles vivem histórias socioambientais das suas identidades sociais, a qual permite através de suas vozes, compreender e dar significado às suas identidades, percepções, anseios e narrativas (Carniatto, 2007). E a análise do conteúdo das respostas da pesquisa seguiu a orientação de Bardin (2016) buscando privilegiar algumas categorias que emergem de suas narrativas.

Portanto, os resultados desta pesquisa são apresentados tendo por referência estudos metodológicos com a abordagem da hermenêutica filosófica e suas contribuições no desvelamento dessas compreensões que fundamentam como alicerce e preocupação a sustentabilidade do ambiente, das pessoas da sociedade e da vida e não tão somente das organizações, almejando à construção de sociedades sustentáveis.

\section{Resultados e Discussão}

\subsection{Fase 1 - Potência da Rede RIPEDRC: Mapeamento Socioambiental das Identidades Sociais dos Pesquisadores}

O projeto de construção da Rede Internacional de Pesquisa Resiliência Climática - RIPEDRC traz uma trajetória de pesquisadores que buscam oportunidades para se engajarem em projetos relevantes e que tragam em seu bojo as possibilidades de atuação destacada na comunidade nacional e internacional.

Busca-se com este estudo, através dos olhares dos pesquisadores, identificar e analisar as potencialidades de cooperação para projetos com atuação em rede, com uma interpretação crítica do projeto CNPq/Fundação Araucária: PI 06/2018 Programa Researcher Links (Reino Unido-Brasil): "Financiamento do Desenvolvimento Resiliente ao Clima", considerando o foco na internacionalização. No exercício da ambivalência de qualquer projeto coletivo, entretanto, buscar-se-á considerar as faces positivas e as riquezas da diversidade plural, da aprendizagem constante e da superação dos obstáculos.

Situa-se este estudo no período de pandemia da COVID-19, a qual trouxe impactos em todas as áreas da sociedade, iniciados principalmente desde dezembro de 2019, mas que persistiu até 2021, e não se sabe quando ou se haverá um término desses efeitos catastróficos.

Importante este contexto, pois que ao contrário do que pressupõe, uma rede que é a da união e trabalho em conjunto, a pandemia promoveu o distanciamento social e isolamento das pessoas, confinando as pessoas em suas casas, com o fechamento das universidades e paralização das demais atividades não consideradas essenciais para a vida. 
A Rede RIPEDRC foi criada como uma parceria de cooperação internacional anterior à crise da Pandemia COVID19, mas para enfrentar o desafio de atuação conjunta dos pesquisadores ${ }^{1}$. Assim, num universo desafiador os pesquisadores da Rede RIPEDRC buscam nesta organização em rede trilhar juntos caminhos de profissionalização e internacionalização de suas universidades.

Portanto, nas atividades da rede busca-se desenvolver laços de aprendizagens coletivas, companheirismo, ajuda mútua, amizade e acolhimento, numa proposta de superar os desafios em épocas tão difíceis como estamos atravessando, que foram ainda mais dificultadas pela Pandemia da COVID-19. Inspirados em Layrargues (2020), bem como em Souza \& Sato (2019, p.66) nos asseveram a importância do compromisso social e de que a Justiça Ambiental interliga a Educação Ambiental e a justiça social no compromisso com a superação das desigualdades.

A Rede RIPEDC compõe um mosaico, que pode sugerir a conformação atual que a Rede possui, mas de modo especial deve demonstrar a possibilidade e potência que a rede vislumbra se tornar através de seus projetos, pesquisas e atividades, trabalhando de forma integrada. Isto pode ser demonstrado como resultado do Mapeamento das Identidades dos Pesquisadores realizado, cujas informações, identificação, instituição e localização podem ser obtidas no mapa (figura 2).

Figura 1 - Mapa da Rede Internacional de Pesquisa Resiliência Climática - RIPEDRC.

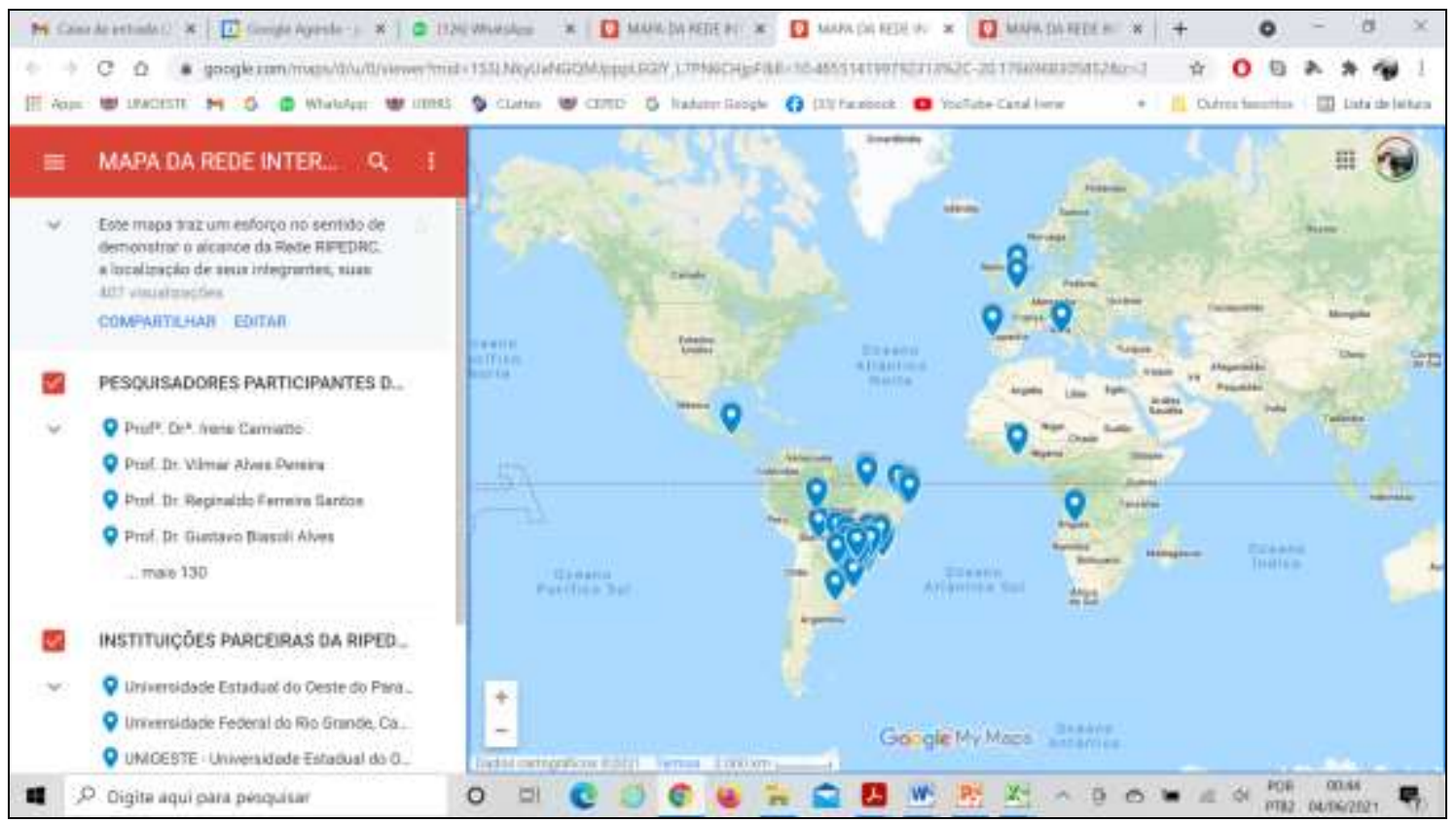

Fonte: Elaborado para esse estudo no Google My Maps. Por Carniatto, 26 jan 2021 e atualizado 01 jul 2021. Acesso em: encurtador.com.br/bkKSU.

Os resultados mostraram que a Rede tem 226 participantes em seu grupo no aplicativo WhatsApp, destes conta com 136 membros que já fizeram sua adesão formalmente e integram esse estudo, os demais participantes ainda não responderam o cadastro. Eles representam 85 diferentes instituições e 13 países: Brasil, Reino Unido, Paraguai, Argentina, Guatemala, Chile, México, Espanha, Itália, Angola, Cuba, Bolívia e Ghana. E a RIPEDRC está presente em 13 estados brasileiros: Paraná, Santa Catarina, Rio Grande do Sul, São Paulo, Rio de Janeiro, Minas Gerais, Mato Grosso, Mato Grosso do Sul, Rondônia, Ceará, Pará, Paraíba e Rio Grande do Norte.

Como se almeja para uma rede direcionada à pesquisa, o grupo de pesquisadores inscritos formalmente na Rede está

\footnotetext{
${ }^{1}$ A coordenação da Rede RIPEDRC e da pesquisa está vinculada à Unioeste/ Centro de Ensino, Pesquisa e Extensão em Proteção e Desastres - CEPED Unioeste, ao Programa de Pós-graduação Doutorado e Mestrado em Desenvolvimento Rural Sustentável, com apoio do o Doutorado e Mestrado em Educação, e o Doutorado e Mestrado em Energia na Agricultura da UNIOESTE (Paraná-Brasil)
} 
composto por 39,70\% de doutores, total de 54 sendo 43 doutores e 11 pós-doutores (Figura 3). Estamos investindo na formação de novos pesquisadores, $45,85 \%$ são doutorandos, mestres e mestrandos que integram os programas de pósgraduação.

Figura 3 - Formação dos pesquisadores participantes da Rede RIPEDRC, por titulação e sexo, junho 2021.

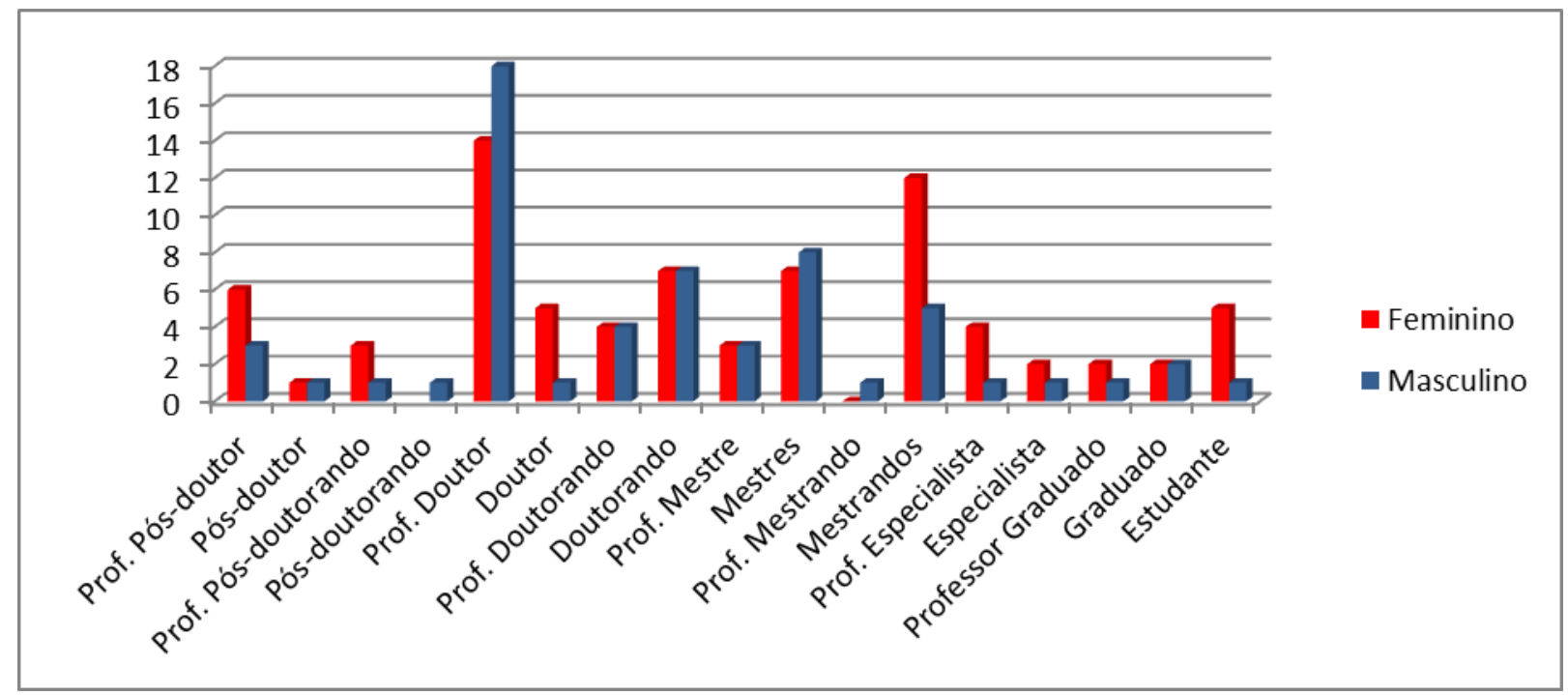

Fonte: Autores com dados desta pesquisa.

Destaca-se também, que a maioria atua como professores, sendo 45 de Doutores e Pós-doutores, e 16 são Doutorandos, Mestres e Mestrandos em Universidades ou Institutos Federais, tanto no Brasil como em outros países.

Também, fica nesta pesquisa confirmada a tendência atual de aumento no quadro de mulheres participantes dos programas de pós-graduação, pois temos 62 mulheres e 53 homens dentre os Pós-doutores, Pós-doutorandos, Doutores, Doutorandos, Mestre e Mestrandos.

No Brasil os dados da Pós-graduação de acordo com os dados da Coordenação de Aperfeiçoamento de pessoal de Nível Superior (CAPES) apontam que "dos 364 mil alunos de mestrado e doutorado no Brasil, 195 mil são mulheres. Entre os matriculados em cursos stricto sensu, elas representam 53\%, além de serem 57\% dos bolsistas da CAPES” (Brasil, 2020, p.1).

Agregam-se também, um grupo menor (14,45\%) que são os especialistas, profissionais graduados e alunos de cursos de graduação, que atuam como colaboradores, mas considerados muito importante, pois são técnicos em prefeituras e órgãos governamentais, ONGs e professores em escolas do ensino básico.

\subsection{Fase 2 - Pesquisa contribuição na rede ripedrc: sentidos e potencialidades}

Considerando o universo desta pesquisa e o caráter qualitativo do estudo, são apresentados na continuidade os resultados da pesquisa com uma mostra de 10 pesquisadores convidados, cujas narrativas constituem os dados e serão apresentados segundo categorias definidas. Suas narrativas são assumidas enquanto representantes dessa realidade complexa que a rede reúne, com diferentes países, culturas e percepções, buscando revelar as contribuições dos pesquisadores na atuação nos seus territórios e instituições aos quais pertencem.

Nessa amostra temos 06 países representados: 01 pesquisador da Guatemala, 01 de Campeche-México, 01 de Santa Cruz-Bolívia, 02 do Reino Unido-UK (01 de Yorkshire e 01 Berkshire) 01 de Bié-Angola, 04 do Brasil (01 do Rio Grande do Sul, 02 do Paraná, 01 de Minas Gerais).

Buscando identificar os pontos considerados positivos e compreender como a atuação em rede pode potencializar as contribuições dos pesquisadores, observa-se que olhando para a formação, o mosaico apresenta com distintas formações, sendo 
um Médico especialista em Saúde Pública, quatro são Doutores em Educação, um Doutor em Ciência Política, um Engenheiro Agrônomo, um Engenheiro, um Doutor em Transformações Urbanas Sustentáveis e outro Doutor em Promoção da Saúde.

Considerando que a Rede está voltada à Sustentabilidade, foi perguntado aos participantes se possuíam alguma formação específica nessa temática, 7 responderam que sim e 3 responderam que não. Também, informaram que possuem formação em Resiliência aos Desastres e Mudanças do Clima, Leitura dos ODS, 3 responderam cursos em Gestão Ambiental, também Vigilância Ambiental, Perícia e Auditoria Ambiental, Transformações Urbanas Sustentáveis, Prática de Sustentabilidade no Ambiente Construído, e teve um participante que nos esclarece que sim e acrescentou:

Toda minha formação é voltada para isso. Além da formação acadêmica básica (graduação, mestrado e doutorado) tenho vários cursos complementares (especializações, aperfeiçoamento, formações, atualizações) na interface entre ambiente e saúde, gestão, educação (Pesq6).

Observa-se o alto nível de formação dos participantes da RIPEDRC, conforme já apresentado, e que os pesquisadores desta mostra são todos doutores, altamente qualificados, formadores de pessoal, produtores de conhecimento e formadores de opinião.

Existem nuances importantes quando se busca compreender as trajetórias e as atuais experiências profissionais desses pesquisadores. Eles relatam que todos são ou foram professores Universitários e atuam nas seguintes instituições: "Universidade Internacional do Cuanza - Angola" (Pesq2); "Engenharia Elétrica e Eletrônica na Hallam Sheffield University, Reino Unido" (Pesq7); "Atuei em universidades privadas PUC, FIOCRUZ e UCAM, atualmente sou docente da Universidade Federal da Integração Latino-Americana, a UNILA” (Pesq6); "Universidade Estadual do Oeste do Paraná (Campus de Toledo, PR) (Pesq3); professor do IFSULDEMINAS (Pesq8); Professor no Doutorado e mestrado no México e Moçambique (Pesq4); Kingston University of London, Reino Unido e University of Central Lancashire, Reino Unido (Pesq10).

Destaca-se que um dos objetivos iniciais da Rede foi o de reunir pesquisadores do Brasil e do Reino Unido, integrando os do Paraguai e Argentina, buscando de um lado unir em colaboração Norte Global e Sul Global e fortalecer a parceria e pesquisa Sul x Sul Global, como apresenta a pesquisadora:

Para aumentar a capacidade de pesquisa e inovação dos pesquisadores em início de carreira, startups e partes interessadas específicas, e aumentar a visibilidade e o entusiasmo em torno da colaboração no Sul Global e Norte Global, e dentro, entre e além dos países de renda baixa, média e alta. Queremos que todos os parceiros da Rede RIPEDRC se envolvam entre diferentes disciplinas e Objetivos de Desenvolvimento Sustentável e Resiliente ao Clima (Pesq10).

E, continua vivo na rede o objetivo de contribuir com os pesquisadores em início de carreira e potencializar suas pesquisas, como reconhece a pesquisadora. Este foi um dos objetivos definido para o financiamento do Projeto do Workshop Brasil-Reino Unido, no qual foi criada a Rede RIPEDRC. Assim, foram iniciados grupos de trabalho para impulsionar a carreira de Jovens pesquisadores com menos de 10 anos de doutoramento e a formação de novos pesquisadores que são os que estão nos programas de doutorado e mestrado.

\subsubsection{Fatores Limitantes}

\subsubsection{Categoria: Desafios de Conectar Pessoas e Grupos que Trabalhem Juntos}

Os desafios são enormes, talvez o primeiro seja conectar pessoas "o desafio da REDE é talvez prospectar grupos que trabalhem juntos e a disseminem o debate na rede" (Pesq2). Mas os objetivos precisam ser cuidadosamente definidos "A cooperação internacional em si é boa, mas os objetivos precisam ser claros desde o início para orientar a parceria" (Pesq7).

Sob a ótica dos pesquisadores participantes quais os desafios e de que maneira é possível superar as dificuldades e transpor as barreiras identificadas. Eles nos informam que em "uma rede internacional aparecerá problemas de língua, horários e culturas que devem nos trazer a grande e maravilhosa diversidade que é o ser humano e o quanto se pode aprender com isso" 
(Pesq3). "Es importante el apoyo de otros para poder avanzar, en especial en mi país que no se tiene recursos para este fin y el gobierno no prioriza apoyo en estos sectores" (Pesq5). Quanto aos aspectos negativos "es que muchas veces la cooperación exige niveles de resultados muy altos o que no condicen con la realidad del país o sector donde se implementa un apoyo" (Pesq5).

Mas a meta de uma visão de cooperação integradora Sul x Sul tem sido desenvolvida integrando 07 diferentes países: Brasil, Paraguai, Argentina, Chile, Bolívia, Angola e Ghana, estamos desenvolvendo parcerias da América Latina com o continente da África. Os nossos pesquisadores nos alertam que "faltam, no entanto, os 'conhecimentos e habilidades' para 'integrar' e 'fazer uma rede' destes ingredientes fundamentais do desenvolvimento de capacidades de forma orgânica, em tempo real e inovadora", "e dentro, entre e além de países de baixa, média e alta renda". Por isso, "ijes necesario un diálogo sincero para avanzar y que sea efectivo y sostenible el apoyo que brindan!!" (Pesq5).

Mas qual o alcance que pode ser impresso aos projetos da rede? Os pesquisadores nos respondem que "o Sul Global e o Norte Global precisam progredir constantemente na capacidade de pesquisa, mas uma barreira importante para a pesquisa é a falta de evidências empíricas sobre intervenções transdisciplinares estratégicas" (Pesq10). Estas intervenções estratégicas apontam para projetos estruturantes que abarcam os especialistas das diversas áreas, contribuindo cada qual com seu campo de conhecimento e potencializando as ações e resultados desses projetos. Uma rede possibilita isso, pois reúne profissionais, na RIPEDRC são 7 países do Sul (citados acima) e 5 países do Norte (Reino Unido, México, Espanha, Itália, Cuba, Guatemala), de inúmeras áreas buscando soluções criativas entorno de um tema de pesquisa.

E traz-nos um lembrete quanto aos necessários resultados práticos para a comunidade, "mas é preciso entender que as pesquisas devem ter caráter prático e que a extensão de seus resultados a toda a sociedade é fundamental” (Pesq3). E, "acredito que a cooperação internacional é importante para a melhoria do meio ambiente através de pesquisas, convênios, acordos entre diferentes organizações" (Pesq4).

Muito tem se debatido do conceito de Novo Normal, diante da Pandemia e as limitações adaptativas que ele possui. Existe um desafio posto diante da Rede RIPEDRC no sentido de como estruturar e mobilizar as pessoas para uma nova estrutura social que não seja baseada nesse Novo Normal, o qual não queremos.

\subsubsection{Categoria: Desafios da Comunicação}

A interação de um grande grupo de pessoas, de diferentes nacionalidades, apresenta enormes desafios a serem enfrentados. Dentre as dificuldades identificadas destacam-se as que envolveram os processos de diálogos, como a deficiência comunicativa em função dos diferentes idiomas; o deslocamento pelas distâncias geográficas; e as diferentes formas de pensamento, também "sinto dificuldades de aprendizagem com o Reino Unido e não apenas pelo idioma, mas pela afetividade, sinto eles muito formais" (Pesq2).

A barreira idiomática é a maior dificuldade inicial. Dentre os pesquisadores da América Latina não há maiores problemas de comunicação todos entendem razoavelmente bem tanto o espanhol como o português. No entanto, poucos falam inglês e em contrapartida os ingleses não entendem nem o Espanhol ou o Português, existe apenas um pesquisador do Reino Unido que entende Espanhol. Como diz o pesquisador "Las barreras de idioma y brechas tecnológicas no permiten un diálogo equitativo" (Pesq1).

Para isso, é necessário respeito à pluralidade, criando formas democráticas, circulares e que proporcionem o diálogo e a comunicação. (Costa, et al., 2020, p.36).

Assim, em cada uma das reuniões, atividades e nos eventos foi necessário organizar em paralelo uma equipe de tradutores de inglês x português e português x inglês, o que dificulta sobre maneira toda a logística de comunicação e duplica o 
tempo da atividade.

Foi posta em prática no Workshop Brasil Reino Unido a solução de organizar uma equipe de aproximadamente 30 alunos e professores que atuaram todo o tempo como intérpretes e acompanhantes dos visitantes, nas visitas técnicas e demais atividades, e para o evento contratou-se uma empresa de tradução simultânea.

\subsubsection{Categoria: Desafios da Pandemia Covid-19}

Também, as dificuldades de como a pandemia afetou o ritmo das colaborações internacionais foram levantadas, pois atividades em andamento na rede tiveram que ser adiadas.

Um pós-doutoramento que seria iniciado na Universidade de York no ano de 2020 teve que ser cancelado.

O Pesq7 diz "Sim. Existem discussões em andamento sobre áreas potenciais de colaboração. Isso foi amplamente interrompido pelo COVID-19”. Esta fala do Pesquisador 7, se refere aos resultados das articulações da Rede RIPEDRC iniciadas no I Workshop UK- Brasil, quando o pesquisador da Universidade de Sheffield esteve no Brasil e conheceu as pesquisas desenvolvidas por uma equipe da Unioeste sobre o carro elétrico. Como oportunidade de parceria, ele fez o convite e foi iniciado o embrião de uma parceria Unioeste e a Hallan Sheffield University do Reino Unido, cujos resultados são apresentados no item 3.2.2.4.

\subsubsection{Potencialidades}

\subsubsection{Categoria: Oportunidades de Trabalho em Rede}

Objetivando conhecer e identificar os pontos considerados positivos e os principais méritos sentidos no contexto da internacionalização através da narrativa das percepções dos pesquisadores, que se indagou sobre as potencialidades da Rede RIPEDRC enquanto espaço internacional de oportunidades.

Eles destacaram que são importantes os "Intercambio de conocimientos y buenas prácticas" (Pesq1); "A Rede é fundamental para isso! Tem sido um espaço muito bom para troca de experiências, de perspectivas e de visões!" (Pesq3). Também, a importância para proporcionar aprendizagens coletivas, com o crescimento acadêmico e profissional dos participantes foi ressaltada quando o Pesq2 acrescenta que "a rede contribui na ampliação de horizontes e de conhecimento de contextos outros que muitas vezes estavam na invisibilidade. Nesse sentido destaco maior aprendizagem sobre nossa América Latina e o conhecimento sobre o espaço trinacional".

Ganhar novos domínios de pesquisa foi lembrado pelo Pesquisador7: "ser membro da rede oferece oportunidade de interagir, compartilhar conhecimento e ganhar novas perspectivas de diferentes domínios de pesquisa". E que "a importância da rede para os nossos projetos é vital porque a interação e formação para novas aprendizagens será parte das bases solidas do conhecimento das pessoas" (Pesq9).

O autor Aleksander Kopka (2020), nos traz à lembrança que não podemos existir, sem o outro, é na relação com o outro que nos constituímos sujeitos, ele diz:

Cada existência não pode ser trazida à existência de outro modo a não ser como compartilhar (para fora): "Se ser é compartilhar, nosso compartilhar, então 'ser' (existir) é compartilhar" (Nancy,1993b, 72), ou ainda, "ser abandonado nesta partilha" (Nancy, 1990, 243). Ao compartilhar (out), portanto, não se chega como sujeito pré-constituído, mas, por meio da partição e da participação, inscreve-se no espaço livre dos movimentos e dos encontros (Kopka, 2020).

Um destaque importante sobre o espaço de formação pela rede pode ser evidenciado na fala de um pesquisador, que reconhece não ter formação anterior em sustentabilidade, mas diz: "Não, mas estou adquirindo conforme os trabalhos da Rede vão avançando!” (Pesq3). Isso já se torna um feedback positivo, em favor do trabalho em que a RIPEDRC vem desenvolvendo. 
Para fazer frente à justiça social e qualidade de vida requer medidas protetivas no enfrentamento da crise sociopolítico-ambiental que estamos atravessando, é muito importante o investimento na formação de pessoas, e observa-se que as comunidades pequenas e médias, muitas vezes são mais vulneráveis aos impactos climáticos e carecem de recursos humanos, materiais e financeiros bem como capacitação de seus gestores e cidadãos (Carniatto, Sakai \& Sakai, 2019).

Nestes tempos de dificuldades e crise é bom que a rede se constitua um espaço de acolhimento, isso é demonstrado na narrativa "tenho observado o movimento e a alegria com que as pessoas se envolvem e se organizam" (Pesq6). Como processos formativos de sonhos, lutas e esperança.

Buscamos promover os processos formativos e de comunicação para darmos audiência de nossas pesquisas sobre a emergência climática. Com ênfase na identidade de mulheres negras, buscamos construir as políticas públicas que possam incluir pessoas em situação de riscos, considerando suas histórias, sonhos e lutas de vidas. Por meio da fenomenologia, construímos a pesquisa com cuidado humano, das demais vidas e das não vidas que se conectam e asseguram os direitos da Terra (Souza \& Sato, 2019, p.59).

Importante abrir espaços de diálogos para se dar voz e vez às pessoas, permitindo o seu empoderamento enquanto cidadãos de direitos, que lutam, almejam e sonham.

\subsubsection{Categoria: Oportunidades para Formação e Expandir seus Contatos/Links}

Se a Rede RIPEDRC tem proporcionado espaço e oportunidades para interação, formação, expandir seus contatos/links, foi perguntado, e como cada um tem percebido e se apropriado desses momentos da rede. Eles respondem positivamente que "A Rede é ótima para isso, pois esta filosofia é o cerne de toda a sua atuação" (Pesq3). "Eu sempre ficarei agradecido por me incluir nesta rede para oportunidades de contatos em várias partes do mundo" (Pesq4). E como juntos vamos criando a compreensão de construir futuros sustentáveis.

A Rede RIPEDRC é muito importante para fornecer aprendizagem coletiva. Tenho aproveitado as vantagens do networking, das interações, da formação e da expansão dos meus contatos / ligações, bem como da aquisição de novas aprendizagens atuais e perspectivas futuras de forma adequada através dos momentos no espaço internacional de oportunidades proporcionadas pela rede. Ganhei a compreensão da importância de construir futuros sustentáveis globais, que foi compartilhada por várias pessoas que conheci por meio da Rede (Pesq10).

As novas aprendizagens atuais e perspectivas futuras representam um grande potencial para as redes, quando responderam que "Uma grande oportunidade para ter melhores e maiores pesquisas que servem as nossas comunidades" (Pesq4). O trabalho em Rede pressupõe a oportunidade de juntos trabalharmos para enfrentar a emergência climática. Importância fundamental de estimular a resistência, deixando evidente a emergência de uma educação para as mudanças climáticas.

Busca-se superar a realidade concreta, aquilo que se apresenta de forma imediata: a miséria, a pobreza, a opressão, as condições aviltantes de produção da existência material (do corpo) e simbólica (a cultura) (Costa, et. al., 2020).

Que a rede serve de inspiração e lança fundamento para outras redes, podendo se constituir no futuro em uma Rede de Redes: "Inspirado por esta rede, eu comecei o Global Sustainable Futures: Progress through Partnerships Network" (Pesq10). Também a cooperação global como uma iniciativa da rede foi lembrada "a cooperação exibida por meio da Rede internacional pode servir como um veículo, uma plataforma global, para fazer melhorias iniciais na obtenção de futuros sustentáveis" (Pesq10).

A rede é percebida enquanto espaço de sinergia, acolhimento, ser aceito, se sentir parte de um grupo, e permite “capilarizar as melhores práticas, conceitos, métodos com mais agilidade e abrangência, gerando novas combinações, inspirações e sinergias" (Pesq6). Eles nos informam "destaque também para forma acolhedora e humanizadora da mediação da 
rede. Isso favorece muito para aproximações, bem como para a efetivação do diálogo e das aprendizagens" (Pesq2). E "precisamos de uma cooperação técnica e troca de saberes, mas de forma acessível para que todos possam de fato sentir-se acolhido" (Pesq8).

Existem outros movimentos que também primam pelo pertencimento e troca, por exemplo, o Imaginamundos é um desses movimentos.

Imaginamundos é um impulso para a defesa da vida e da compreensão da interdependência e da impermanência, ou seja, a característica ecossistêmica dos seres vivos. Todos os seres vivos estão conectados ecossistemicamente entre si, trocando matéria e energia constantemente, fazendo a roda da vida girar no seu ciclo de nascimento, reprodução e morte. Desencantamento pode ser sinônimo de morte existencial, imaginar correto é se encantar. Como nos afirmam Luis Antonio Simas e Luis Rufino, em Flecha no tempo, "[...] o contrário da vida não é a morte, mas o desencanto" (Simas \& Rufino, 2019, p. 5 apud Costa, et. al., 2020).

Como também nos ensinou o grande Mestre Paulo Freire "Não entendo a existência humana e a necessária luta para fazê-la melhor, sem esperança e sem sonho" (Freire, 1992, p.5). Florescer o encantamento e sonho é componente essencial da vida.

\subsubsection{Categoria: Oportunidade de Interação e Cooperação}

Numa relação dialógica entende-se que uma rede é um instrumento que pressupõe interação e possivelmente cooperação, buscou-se qual o significado de cooperação atribuído por esses pesquisadores participantes do estudo, na pretensão de compreender seus anseios e como potencializar suas interações identificando os pontos considerados positivos.

Os pesquisadores definem a cooperação como "é ação colaborativa, em que cada um doa o que tem de potencial, disponibilidade, competência, a partir de um horizonte e desejo comum" (Pesq6). E "cooperar é compartilhar o que sabemos que pode servir para alguém" (Pesq9). Para alguns, imbrica-se com a sua filosofia de vida, pois, "para mim a experiência de cooperação é tão importante como a missão de cada pessoa neste mundo" (Pesq4). "É disposição para cultivar pacientemente os objetivos e mudanças almejados, com espaço para o crescimento e desenvolvimento de todos e todas" (Pesq6).

E como é esta cooperação em uma rede internacional, segundo a compreensão dos pesquisadores ouvidos? Acreditase que "sim, a atuação em redes é fundamental, cada vez mais. Ampliam a escala e o alcance das ações, a consistência e a força das construções" (Pesq6). "Esta rede internacional é excelente para realizar pesquisa e aprendizagens coletivas" (Pesq9). E que a Rede RIPEDRC permite o "desenvolvimento de parcerias multidisciplinares oferecidas por meio da rede permite o desenvolvimento de capacidades, vínculos mais fortes entre pesquisa, política e prática” (Pesq10).

Neste sentido busca-se romper com a heteronomia (consciência ingênua) e produzir a consciência crítica (autonomia e emancipação), inspirado em Paulo Freire com uma participação libertadora, que luta, enfrenta e constrói outros futuros possíveis (Costa, et. al., 2020).

Pode a Rede apresentar potencialidades e espaços de crescimento coletivo, as contribuições são que "a REDE é um espaço potencializador de projetos que já temos e de ampliação de outras possibilidades de internacionalização” (Pesq2).

\subsubsection{Categoria: Oportunidade de Cooperação - Resultados da Rede RIPEDRC}

As oportunidades de cooperação estão nos horizontes da Rede. A cooperação Brasil com países do Reino Unido foi iniciada com os trabalhos do projeto do Workshop Reino Unido - Brasil, financiado pelo Council British, UK e pela Fundação Araucária do Paraná, Brasil.

Os frutos já estão aparecendo. Mas a fim de responder se a Rede tem crescido e se desenvolvido, mesmo diante dos desafios da pandemia, entre outros, é necessário buscar elementos de seu histórico.

O primeiro resultado consta da organização conjunta do I Workshop UK - Brasil Financiamento do Desenvolvimento Resiliente ao Clima, em setembro de 2019, o qual contou com 350 participantes, sendo 50 residentes locais, 220 de outros 
municípios/estados e 80 de outros países. Também a criação da Rede RIPEDRC, assinando sua adesão 76 pesquisadores presentes, representantes de 46 instituições.

Ainda, em 2019, a rede realizou a I Oficina da Rede Resiliência Climática, nos dias 12 e 13 de dezembro de 2019, com palestras e discussão das demandas em 09 grupos de trabalho, quando foi criado o Consejo Latinamericano Sociedad 5.0 + Paraguay + Brasil - Cidades Resilientes (Figura 4).

Figura 4 - Figura da região compreendida pelo Projeto Megalópoles da Tríplice Fronteira (Paraguai, Argentina e Brasil).

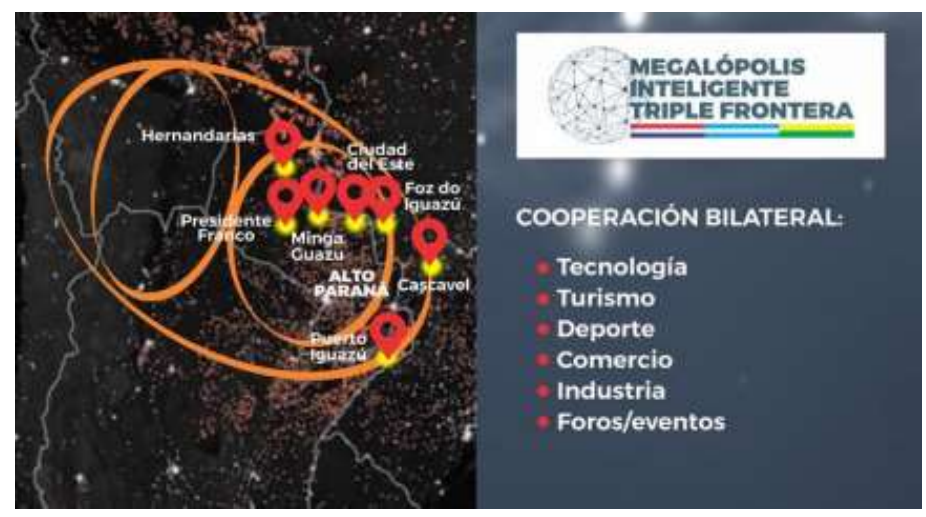

Fonte: Carniatto et al, (2020). Créditos do Coordenador do Projeto Juan Enrique Szymankiewicz.

Nessa mesma oficina participaram 60 pesquisadores e gestores públicos do Brasil, Paraguai e Argentina, na busca por organização de Projetos Conjuntos, um dos quais foi apresentado e a criação da Megalópoles Inteligente da Tríplice Fronteira como um dos programas promissores para a região de fronteira Brasil - Paraguai - Argentina.

Como resultado ainda do I Workshop UK-Brasil foi criada em 2019 a revista International Journal of Environmental Resilience Research and Science - IJERRS (http://e-revista.unioeste.br/index.php/ijerrs/index), que publicou seu primeiro número em 2019 e já publicou 4 números, mantendo uma publicação semestral e no processo da publicação contínua. Sua contribuição alcança mais de 60 artigos, abrangendo o campo da Sustentabilidade.

Em 2020 foi realizada a primeira Viagem Técnica Internacional da RIPEDRC à Europa, buscando o estabelecimento de parcerias em uma universidade de Lisboa, Portugal e 5 Universidades do Reino Unido. As visitas técnicas organizadas por todas as instituições foram muito importantes, com muitos resultados:

1) Participação de 08 componentes da Rede com a coordenação de uma mesa de Trabalhos no III Congresso Lusófono realizado na Universidade Lusófona de Lisboa, Portugal, de 31 de janeiro a 5 de fevereiro de 2020. No GT 2: Religião, Ética e Desenvolvimento Rural Sustentável, coordenado pelos pesquisadores da Rede e professores da Unioeste (Paraná, Brasil) teve 11 trabalhos técnicos apresentados;

2) Foi realizado um Workshop sobre Pesquisas Científicas na University College of Estate Management (UCEM)Reading, UK;

3) Participação em um seminário de 4 dias na Hallan Sheffield University, UK, com participação de mais de 10 palestrantes apresentando seus projetos;

4) Parceria e envolvimento da equipe brasileira da Unioeste na Coordenação no Hackaton 2020, coordenado pela Coventry University, no Reino Unido, e já está em preparativo o Hackaton 2021;

5) Uma reunião técnica na Anglia Rustin University, Cambridge, UK.

Nas 5 (cinco) universidades visitadas foi apresentada uma palestra sobre a atividades da Unioeste e do Centro de 
Ensino, Pesquisa e Extensão em Proteção e Desastres - CEPED Unioeste, os projetos desenvolvidos na Região Oeste e Sudoeste do Paraná, bem como na Tríplice Fronteira Brasil, Paraguai e Argentina, e realizado o convite para pesquisadores participarem da REDE - RIPEDRC.

Destas visitas resultam os trabalhos que estão sendo desenvolvidos com a Universidade de Reading na dinamização e criação de novas redes de pesquisa, com a Coventry já foi realizado o Projeto Hackathon 2020 e o Challenges SDGs 2021 com o desenvolvimento de importantes projetos que preveem contribuir para ODS1 - Erradicação da Pobreza, ODS2 - Fome Zero, ODS4 - Educação de Qualidade, ODS11 - Cidades e Comunidades Sustentáveis. Já foi assinado o acordo de Cooperação entre a Unioeste e a Universidade de Sheffield com parceria para 02 doutorados em conjunto na área de tecnologia e veículos elétricos. No entanto, os planos tiveram que ser adiados devido a pandemia COVID-19, os alunos estão em orientação internacional on-line em conjunto com o orientador brasileiro, aguardando a melhora da pandemia para irem em 2022 desenvolver parte da pesquisa em Sheffield.

Apesar das enormes dificuldades advindas pela pandemia, em 2020 a Rede RIPEDRC se organizou e começou a buscar as ferramentas para mobilização e reuniões formativas On-line. Atualmente a Rede está muito ativa e para alcançar sua comunicação a Rede faz uso do WhatsApp e o e-mail, usa a plataforma Zoom, também possui um site institucional (https://www.unioeste.br/portal/ceped/rede-resiliencia) e o site de sua revista International Journal of Environmental Resilience Research and Science - IJERRS (http://e-evista.unioeste.br/index.php/ijerrs/index), uma conta no Facebook (https://www.facebook.com/unioesteceped), uma página no Instagran (https://www.instagram.com/rede.climatica/).

Compreendemos o espaço da Rede como um espaço de formação, articulação para projetos colaborativos, criar oportunidades para participação internacional conjunta, assim em 2020 foram realizadas 15 Reuniões Formativas quinzenalmente $O n$-line, com palestrantes internacionais e nacionais.

A RIPEDRC contribuiu na organização e participação de eventos como:

O $18^{\circ}$ Congresso Nacional de Meio Ambiente de Poços de Calda, do IFSULMINAS, Minas Gerais, BR, com 1 palestrante e 2 mesas de discussões com 8 pesquisadores.

O $4^{\circ}$ Seminário NUPPAA - Núcleo de Políticas Públicas: Análise e Avaliação, do Instituto Nacional de Ciência e Tecnologia de Políticas Públicas, Estratégias e Desenvolvimento (INCT-PPED) da UFRJ, Rio de Janeiro, BR, dias 16 e 17 de novembro 2020, com a apresentação de 3 trabalhos científicos.

Organização do II Workshop Internacional da Rede de Pesquisa Resiliência Climática - RIPEDRC, nos dias 13 a 15 de dezembro de 2020, (https://www.unioeste.br/portal/ceped/iiworkshop-ripedrc), todas as atividades online, com apresentação de 30 palestrantes, em 10 mesas e 10 GT temáticos com pesquisadores do Reino Unido, Guatemala, Paraguai, México, Uganda, Angola e Brasil, participação de 150 pesquisadores e aluno e quando houve a apresentação e publicação de 60 trabalhos científicos.

Reconhecendo que existe muito para avançar numa gestão pública socioambiental, que realmente nos brindem com a melhoria da qualidade de vida no planeta, acabar com a fome e a pobreza e manter a harmonia do ambiente com a humanidade, que segundo Costa, et. al. (2020) é também produzir mundos.

Utilizamos o arsenal freiriano, para entender que há muito as forças hegemônicas já conhecem e dominam as estratégias sutis, de produzir e operar a cegueira, por meio de uma insistente excitação e entorpecimentos dos sentidos. Educar seria, então, potencializar imaginações? Em tempos atuais, notamos uma disputa de narrativas, visualidades e virtualidades. Contudo, compreendemos que, em lugar de apropriar-se do mundo, é fundamental aprendermos a nos apropriar do ato de imaginar, que é também um ato de produzir mundos. A disputa do imaginário consiste em possibilitar que a nossa capacidade de sonhar e de existir não seja roubada. (Costa, et. al., 2020).

Assim, a Rede RIPEDRC tem sido encarada como um espaço onde através da vivência acadêmica é possível construir 
novas realidades e enfrentar os desafios de nossos territórios, inspirados em Paulo Freire lançamos mão da Pedagogia da Esperança, onde esperançar é um movimento de contínuas atividades abrindo portas para novos atores descobrirem e imaginarem um outro mundo possível.

\section{Considerações Finais}

Partindo-se dos subsídios discursivos na perspectiva dos pesquisadores é possível afirmar que existe uma excelente oportunidade de trabalho no âmbito local e global, que o trabalho em rede permite o desenvolvimento do conceito de "pensar local mais ações globais o que vai ao encontro do trabalho das redes de cunho nacional e/ou internacional" (Pesq8). "São excelentes para pesquisas e para aplicação do conhecimento nas comunidades" (Pesq4). E a pesquisa em rede "estabelece a importância de uma abordagem de sistemas, que são as três prioridades contínuas para pesquisadores do Sul Global: desenvolvimento de capacidades, vínculos mais fortes entre pesquisa, política e prática” (Pesq10).

Também, desde o lançamento da Rede RIPEDRC nossa atenção esteve voltada para a cooperação na América Latina, assim foram convidados pesquisadores do Paraguai e Argentina a iniciarem conosco essa rede a fim de estruturar também a parceria Sul x Sul Global, e os pesquisadores reconhecem e assumem esta perspectiva, "acredito que pode explorar mais os trabalhos dos "Hermanos" latino-americanos" (Pesq2).

A Rede RIPEDRC tem como foco continuar a cooperação Norte Global e o Sul Global, que deu origem à rede. Têm buscado parceiros que possam contribuir com oportunidade de projetos estratégicos e financiamentos para as pesquisas, sendo importante o atendimento aos pressupostos dos desafios hodiernos nos quais "pesquisadores, profissionais da indústria, tecnocratas e instituições orientadas para a pesquisa - respondam às mudanças climáticas contínuas e emergentes, desafios ambientais e de sustentabilidade no Sul Global e no Norte Global" (Pesq10).

O desenvolvimento da formação e a cooperação internacional em nível de pós-graduação são percebidos como muito interessante e definem os motivos para o trabalho integrado em rede "palavra contém em si o cerne da resposta: é co-operar, ou seja, operar junto, trabalho em equipe, sinergia. Devemos atuar junto somando o potencial de cada um de nossos membros na confecção do nosso objetivo comum" (Pesq3). Sim, "porque se contribuye a formar gente experta en estas áreas y conducir procesos de investigación, se debe aprovechar los medios virtuales y trabajar con actores como las universidades y otras instituciones de formación" (Pesq5). E que a "atuação dos pesquisadores com outras IES do mundo já é uma realidade em muitos países. Os benefícios são imensuráveis de aprendizagem" (Pesq2).

Destaca-se que uma rede pressupõe experiências inovadoras, potentes e significativas, o Pesq5 amplia as possibilidades e sintetiza o sentido da rede quando esclarece "Interactuar más en el intercambio de experiencias en la investigación y como enfrentan los problemas en cada pais", e o desenvolvimento de projetos considerados pilotos, ou seja, "experiencias para poder replicarlas o reforzar las que tenemos en el nuestro país", mas precisamos "avanzar en gestión pública ambiental".

Uma rede de pesquisa pode ser um instrumento poderoso de ação e atua-Ação. É construir um espaço acolhendo de forma receptiva todos esses olhares sobre a rede e o que fica reforçado são os desafios sempre presentes de a partir dessas escutas e narrativas estabelecer as parcerias, o trabalho conjunto, promovendo a cooperação mútua, o fortalecimento e internacionalização das Universidades, principalmente os Programas de Pós-graduação, através de pesquisas inter e transdisciplinares, facilitar mobilidade acadêmica, produzir publicações conjuntas, organização de eventos e outros.

Ao mapear as principais potencialidades de uma rede internacional de pesquisa, pudemos compreender a oportunidade na construção de projetos relevantes para nossas comunidades, acolher e contribuir para um Novo Mundo Possível. Pode-se deixar claro que diante dos desafios de um mundo árido, de muito egoísmo, de negacionismo, de falta de solidariedade, alteridade e cooperação, a Ciência pode, deve e tem dado o exemplo de se unir para restituir a saúde e salvar as nossas vidas, 
diante dessa pandemia COVID-19. Também, se os governos incentivarem e apoiarem pode a Ciência ajudar na construção de uma nova sociedade sustentável, justa e solidária.

\section{Agradecimentos}

Ao PPGE/UFMT, PPGRDS/CEPED/UNIOESTE, Council British do Reino Unido e a Fundação Araucária do Paraná, Brasil pelo financiamento inicial da organização da Rede RIPEDRC.

\section{Referências}

Adger, W. N., Arnell, N. \& Tompkins, E. (2005). Successful adaptation to climate change across scales. Global Environment Change Part A, $15,77-86$.

Amaral, M.J., Pereira, V. A. \& Costa, L. B. (2018). Impactos da participação popular na IV Conferência da Igualdade Racial em Rio Grande - RS. Revista Teias, 19(54), 463-477.

Bardin, L. (2016). Análise de Conteúdo. Trad. Luís Antero Reto, Augusto Pinheiro. Edições 79.

Brasil. (2020). No mundo, cresce a participação feminina nas ciências. CAPES. Notícias. https://www.gov.br/capes/pt-br/assuntos/noticias/no-mundocresce-a-participacao-feminina-nas-ciencias.

Boff, L. (2012). As Quatro Ecologias - Ambiental, Política e Social, Mental e Integral. Saraiva.

Carniatto, I. (2007). Subsídios para um Processo de Gestão de Recursos Hídricos e Educação Ambiental nas Sub-bacias Xaxim e Santa Rosa, Bacia Hidrográfica Paraná III. Tese (Doutorado) - Doutora em Ciências Florestais do Programa de Pós-Graduação em Engenharia Florestal, Setor de Ciências Agrárias da Universidade Federal do Paraná. Curitiba.

Carniatto, I., Rosa, M. A. \& Oliveira, W. A. de. (2015). Educação Ambiental para comunidades sustentáveis: Rede paranaense de pesquisa em educação ambiental por bacia hidrográfica, Paraná, Brasil. AmbientalMENTEsustentable. 2(20). 5-19.

Carniatto, I., Sakai, M. \& Sakai, P. (2019). Desenvolvimento Resiliente ao Clima: contribuições do Workshop Reino Unido - Brasil Financiamento do Desenvolvimento Resiliente ao clima. International Journal of Environmental resilience Research and Science (IJERRS), 1(1), 10-23.

Carniatto, I., Oliveira, W. A. de, Santos, R. F. \& Lewandoski, C. F. (2020). Desafios para a Rede Internacional de Pesquisa em Desenvolvimento Resiliente ao Clima - RIPEDRC - Rede Resiliência Climática. International Journal of Environmental resilience Research and Science (IJERRS), 2 (1), 10-23.

Costa, R. N., Sánchez, C., Loureiro, R. \& Silva, S. L. P.da. (Orgs.) (2020). Imaginamundos Interfaces entre educação ambiental e imagens. Editora NUPEM.

Cotta, J. A., Rezende, M. O. O. \& Piovani, M. R. (2006). Avaliação do teor de metais em sedimento do Rio Betari no Parque Estadual Turístico do Alto Ribeira - PETAR. Química Nova. 29(1), 40-45.

Freire, P. (1992). Pedagogia da Esperança: Um reencontro com a Pedagogia do Oprimido. Paz e Terra.

Foster, J.B. (2020). Capitalismo de catástrofe: mudança climática, COVID-19 e crise econômica. Entrevista a Farooque Chowdhury. Retrieved Apr 10, 2020, from https://envolverde.cartacapital.com.br/capitalismo-de-catastrofe-mudanca-climatica-covid-19-e-crise-economica/.

GUPTA, J. (2007). The multi-level governance challenge of climate change. Environmental Sciences, 4(3), 131 - 137.

Kobiyama, M., Mendonça, M., Moreno, D.A., Marcelino, I.P.V.O., Marcelino, E.V., Gonçalves, E.F., Brazetti, L.L.P., Goerl, R.F., Molleri, G.S.F. \& Rudorff, F.M. (2006). Prevenção de desastres naturais: conceitos básicos. Curitiba: Ed. Organic Trading. 109p.

Kopka, A. (2020). Sharing (Out) Democracy. On the Democratic Injunction for Climate Justice. The Polish Journal of Aesthetics, 58 (3), 45-68. $10.19205 / 58.20 .4$

Layrargues, P. P. (2020). Pandemias, colapso climático, antiecologismo: Educação Ambiental entre as emergências de um ecocídio apocalíptico. Revista Brasileira de Educação Ambiental (RevBEA), 15(4), 1-30. https://doi.org/10.34024/revbea.2020.v15.10861.

Leff, E. (2006). Racionalidade ambiental: a reapropriação social da natureza. Civilização Brasileira.

Leff, E. (2011). Saber ambiental. (8a ed.), Vozes.

Loureiro, C. F. B. (2004). Trajetória e fundamentos da educação ambiental.: Cortez.

Lovelock, J. (2010). Gaia: alerta final. Intrínseca.

Manfrinate, R., Sato, M. \& Pazos, A. S. (2019). Entrelaçamentos entre justiça climática e educação ambiental: diálogos com mulheres de comunidades tradicionais do Mato Grosso e Galícia. Pesquisa em Educação Ambiental (Online), 14, 171-191.

Miranda, J. E. de. (2020). Da inovação social à inovação social cooperativa: a proeminência dos valores cooperativos como elementos aptos à transformação sócio-econômico-humana. Conteúdo Jurídico, https://conteudojuridico.com.br/consulta/Artigos/19669/da-inovacao-social-a-inovacao-social-cooperativa-aproeminencia-dos-valores-cooperativos-como-elementos-aptos-a-transformacao-socio-economico-humana. 
Research, Society and Development, v. 10, n. 9, e41910918018, 2021

(CC BY 4.0) | ISSN 2525-3409 | DOI: http://dx.doi.org/10.33448/rsd-v10i9.18018

Morosini, M. (Org). (2017). Dossiê: Internacionalização da educação superior. Rev. Educação. 40(3), $288-289$.

Pereira, V. A. (2020). O que será o amanhã? Educação ambiental na América Latina e Caribe, justiça Ambiental e COVID-19. Garcia.

Pereira, V. A. \& Amaral, M. J. (2020). Ecologia Cosmocena: uma Ecologia Das Diferenças. International Journal of Environmental Resilience Research and Science (IJERRS), 2(2), 29-47.

Reigada, C., \& Tozoni-Reis, M. F.de C. (2004). Educação Ambiental para Crianças no Ambiente Urbano: uma proposta de pesquisa-ação-participativa. Ciência Educação, 10, 149-159.

Sato, M. T. (2014). Mitopoética das águas salgadas. GPEA-UFMT, Relatório parcial de pós-doutorado, 50p., il, (mimeo).

Serantes-Pazos, A. \& Meira-Cartea, P. A. (2016). El cambio climático en los libros de texto de la Educación Secundaria Obligatoria o una crónica de las voces ausentes. Revista Documentación Social, 183, 153-170.

Silva, M. J. da \& Sato, M. T. (2012). Territórios em tensão: o mapeamento dos conflitos socioambientais do Estado de Mato Grosso - Brasil. Ambient. Soc. [online]. 15(1), 1-22. http://dx.doi.org/10.1590/S1414-753X2012000100002.

Souza, C. F. \& Sato, M. (2020). Justiça Climática e Educação Ambiental. In: Pereira, V. A. \& Malta, M. C. (Org.). Ontologia da Esperança: a Educação Ambiental em tempos de crise. 1Editora Garcia, 183p.

Thiollent, M. (2011). Metodologia da pesquisa-Ação. (18a ed.), Cortez.

Wilson, E. (2008). A criação: como salvar a vida na terra. Tradução: Isa Mara Lando. Companhia da Letras.

Zohar, D. \& Marshall, I. (2012). QS: inteligência espiritual. Tradução: Ruy Jungmann. Viva Livros. 